\title{
Characteristics and management of testicular torsion in patients admitted to the Urology Department at Chris Hani Baragwanath Academic Hospital
}

\author{
Alain Mwamba Mukendi ${ }^{*}$ (I), Deirdre Kruger $^{2}$ and Mohamed Haffejee
}

\begin{abstract}
Background: The study was carried out to determine the trend of referrals with testicular torsion; the pre-surgery duration of symptoms; the rate of orchidectomy; as well as the seasonality and the age-related laterality of testicular torsion.

Methods: This was a retrospective study conducted at Chris Hani Baragwanath Academic Hospital using patients' records from 2006 to 2018 from which data were obtained and analyzed.

Results: A total of 308 patients with testicular torsion were included in this study; the mean age was $17.2 \pm 4.12$ (10-33) years. The median (IQR) time from onset to hospital was 47 h, and 194/308 (63\%) underwent orchidectomy. Although the orchidectomy rate was higher (95\%) in those who had surgery beyond $72 \mathrm{~h}, 3.6 \%$ had reperfusion after detorsion in theater followed by orchidopexy. In the 112 patients who underwent a bilateral orchidopexy, the time from onset of symptoms to surgery was significantly shorter at a median (IQR) of 13 (9-26) h, compared to 144 $(40-264) \mathrm{h}$ in the 194 patients who had an orchidectomy $(p<0.0001)$. The odds of presenting with a right -sided testicular torsion increases by $6 \%(p=0.047)$ for every 1 -year increase in age.

Conclusion: This study shows that there is a significant association between the pre-surgery duration of symptoms and the testicular salvage rate. Testicular salvage is possible beyond $72 \mathrm{~h}$ from the onset of symptoms, although the salvage rate reduces from $75 \%$ within $24 \mathrm{~h}$ to $3.6 \%$ beyond $72 \mathrm{~h}$. In addition, it also shows that older patients tend to present with right-sided torsion.
\end{abstract}

Keywords: Testicular torsion, Orchidectomy, Orchidopexy, Manual detorsion, Trend

\section{Background}

Testicular torsion refers to the twisting of the spermatic cord structures with the subsequent loss of perfusion to the homolateral testicle. It is a urological emergency; early diagnosis and surgery are vital to saving the testicle and preserving future fertility $[1-3]$.

\footnotetext{
*Correspondence: alainmwamba2006@yahoo.fr

1 Division of Urology, Department of Surgery, School of Clinical Medicine, Faculty of Health Sciences, University of the Witwatersrand, Johannesburg, South Africa

Full list of author information is available at the end of the article
}

Recent studies demonstrated that duration of symptoms prior to presentation to hospital was the most significant factor in predicting outcomes in patients with acute testicular torsion. Delayed presentation puts patients at risk of orchidectomy [4].

In addition, previous investigations on the seasonality of testicular torsion have shown conflicting results where some studies found a positive association between cold weather and testicular torsion and others found no association [5].

Incitingly, the following observations over a two-week period in the winter of 2013 constituted the motivation 
to conduct this study: an increased number of referrals of patients with testicular torsion to the Department of Urology at Chris Hani Baragwanath Academic Hospital (CHBAH); a high rate of testicular loss (orchidectomy); patients younger than 16 years of age all had a left-sided torsion; and the understanding that during this time period, lack of awareness, misdiagnosis and delayed referral of patients with acute scrotum from referring centers caused delayed presentations to CHBAH.

The purpose of this retrospective study was primarily to determine the yearly trend in number of referrals, to assess the time frame from onset of symptoms to the arrival at hospital and from arrival at hospital to surgery and, finally, to determine the rate of manual detorsion, testicular salvage and/or orchidectomy. Secondary objectives were to determine whether seasonality of testicular torsion existed, report on age at presentation and side of the torsion.

\section{Methods}

This study was conducted at the Department of Urology at Chris Hani Baragwanath Academic Hospital (CHBAH). The CHBAH is the largest tertiary hospital in South Africa, situated in Soweto, and one of the largest hospitals in the world. The study was designed as a retrospective cohort study using patients' medical records from 2006 to 2018.

Ethical approval was obtained from the University of the Witwatersrand Human Research Ethics Committee (HREC) ahead of the outset of the study (Clearance Number M190761). Permission had also been obtained directly from the Head of Department of Urology at $\mathrm{CHBAH}$ as well as from the Chief Executive Officer (CEO) to make use of stored medical records. The study procedures were in accordance with the Declaration of Helsinki of 1964 and its recent revision in 2013.

The study enrolled all patients from 10 years old and above with accessible records admitted to the CHBAH Department of Urology who underwent scrotal exploration, orchidopexy or orchidectomy from 2006 to 2018 for testicular torsion. Patients under 10 years old are managed by pediatric surgeons as per hospital policy and interdepartmental agreement.

Data were collected retrospectively from patients' records and were de-identified to preserve confidentiality of research participants. Theater register books were used as the starting point to search and identify cases. Scrotal exploration, orchidectomy and orchidopexy were keywords.

Files were requested and only those of testicular torsion patients were selected and considered for the study. In total, 351 patients' records were retrieved. Only 308 records of patients with testicular torsion were enrolled in the study as the remaining 43 had surgery for either undescended testis or penetrating scrotal injury; hence, they were not included.

The collected data included age at admission, month of admission, year of admission, cause of torsion, side of pathology, preadmission duration of symptoms, manual detorsion, duration from admission to surgery and the type of surgery (orchidopexy or orchidectomy). Preadmission duration of symptoms and time of admission were found on the first page of the admission blue file, control chart and nursing progress report. The duration from admission to surgery was the difference between the time of admission and the time of surgery which was found on the anesthetic chart or theater notes.

These data were stored in an Excel spreadsheet with each entry given a unique identifier to which only the researchers had access to. The data were imported into Stata Statistical Software version 14 for analysis. Time frame data were not normally distributed due to time extremes, and hence, we report medians and interquartile ranges (IQRs).

The descriptive statistics including categorical variables are summarized in frequencies and percentages, while the continuous variables are analyzed and presented using either the median and IQR, or the mean $( \pm S D)$. The chi-squared test was used to examine the seasonality and laterality of the condition. A value of $p<0.05$ was regarded as being statistically significant.

\section{Results}

The total number of patients with testicular torsion included in this study was 308 . The mean age was $17.2 \pm 4.12$ years and ranged from 10 to 33 years. Two patients in the study presented with atrophied testis following testicular pains months before (reason for consult) and had orchidopexy of the contralateral side. Another patient had non-simultaneous bilateral torsion (one year apart) and only consulted 7 days after the onset of the other side. The yearly number of referrals is shown in Table 1, and the trend is displayed in Fig. 1, with the lowest number of 1 referral in 2007 and the highest referral of 41 patients in 2013. On average, 24 patients were referred per annum during the 13-year study period. During this period, $42.5 \%$ were younger than 16 years of age, while $57.5 \%$ were older than 16 years. The majority of patients presented in the winter (Table 1).

In terms of the onset of symptoms, $96 \%$ of cases had a spontaneous onset, whereas the remaining $4 \%$ were trauma related.

During the study period, the time from the onset of symptoms to hospital admission was a median (IQR) of $36(10-168) \mathrm{h}$; the time from hospital admission to 
Table 1 Characteristics of patients that presented with testicular torsion at the $\mathrm{CHBAH}$ urological unit from 2006 to 2018

\begin{tabular}{ll}
\hline Characteristics & Frequency (\%) \\
\hline Age, years, mean \pm SD & $17.2 \pm 4.12$ \\
Age & \\
$<16$ & $131(42.5)$ \\
$\geq 16$ & $177(57.5)$ \\
Season of the month & \\
Summer & $60(19.5)$ \\
Autumn & $80(26)$ \\
Winter & $93(30.2)$ \\
Spring & $75(24.3)$ \\
Year & \\
2006 & $4(1.3)$ \\
2007 & $1(0.32)$ \\
2008 & $23(7.5)$ \\
2009 & $10(3.2)$ \\
2010 & $14(4.5)$ \\
2011 & $32(10.4)$ \\
2012 & $24(7.8)$ \\
2013 & $41(13.3)$ \\
2014 & $34(11)$ \\
2015 & $34(11)$ \\
2016 & $34(11)$ \\
2017 & $29(9.4)$ \\
2018 & $28(9)$ \\
\hline
\end{tabular}

surgery was a median (IQR) of $6(3-48) \mathrm{h}$ and from the onset of symptoms to surgery was 47 (15-216) h.

Impressively, when considering only patients taken to theater within $72 \mathrm{~h}$ of onset of symptoms, the median (IQR) times improve. The median (IQR) time from onset of symptoms to hospital decreased to $12 \mathrm{~h}$ (7-24); the median (IQR) time from admission to surgery also decreased to $3 \mathrm{~h}(2-5)$ as well as the median (IQR) time from onset of symptoms to surgery down to $16 \mathrm{~h}$ (10$28)$. Of the 308 study patients, $51.6 \%(n=158)$ had leftsided torsion, $48 \%$ had right-sided torsion $(n=148)$, and one patient $(0.3 \%)$ had bilateral torsion. From Table 2, the mean age $( \pm S D)$ for those with left-sided testicular torsion was 16.74 $( \pm 3.85)$ and for those with right-sided torsion was $17.67( \pm 4.37)$. Left-sided torsion was more frequent in those younger than 16 years (57.3\%), while right-sided torsion was more frequent in those aged 16 years and older $(52.8 \%)$. Specifically, a trend was seen in patients aged $\geq 16$ years that they were more likely to present with right-sided testicular torsion compared with those $<16$ years of age (OR 1.50, 95\% CI 0.95-2.37), albeit not statistically significant $(p=0.08)$. Moreover, we found that for every 1-year increase in age, the odds of presenting with a right-sided testicular torsion increases by $6 \%$ (OR 1.06, 95\% CI 1.00-1.12, $p=0.047$ ) (Table 2).

Winter was the season with the highest number of referrals (30.2\%) and summer with the lowest number of referrals (19.5\%) (Fig. 2 and Table 1). Even though testicular torsion was seen more in winter in both age groups ( $26.7 \%$ in those $<16$ years and $32.77 \%$ in those $>16$ years), it was not statistically significant $(p=0.480)$ (Table 3$)$.

Of the 308 study patients, 112 (36.4\%) patients underwent bilateral orchidopexy, 194 (63\%) orchidectomy

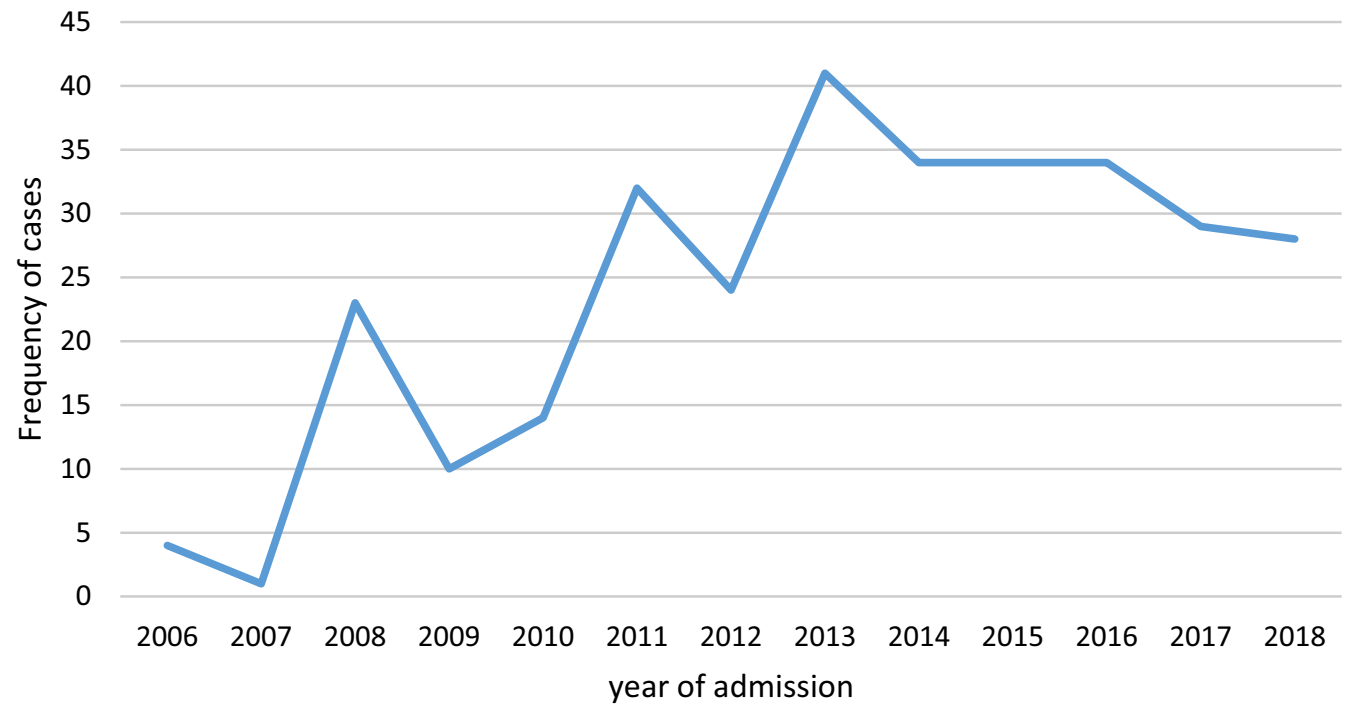

Fig. 1 Trend of number of testicular torsion cases over the study period 
Table 2 Association of age with laterality of testicular torsion

\begin{tabular}{|c|c|c|c|c|c|}
\hline & \multicolumn{5}{|c|}{ Laterality of testicular torsion } \\
\hline & Left $(N=158)$ & Right $(N=149)$ & Total $(N=307)$ & OR $(95 \% \mathrm{Cl})$ & $P$ value \\
\hline Age, years, mean $\pm S D$ & $16.74 \pm 3.85$ & $17.67 \pm 4.37$ & $17.19 \pm 4.13$ & $1.06(1.00-1.12)$ & 0.047 \\
\hline Age, years & $n($ row \%) & $n($ row \%) & n (column \%) & & \\
\hline$<16$ & $75(57.3)$ & $56(42.7)$ & $131(42.7)$ & 1.00 (Ref) & 0.080 \\
\hline$\geq 16$ & $83(47.2)$ & $93(52.8)$ & $176(57.3)$ & $1.50(0.95-2.37)$ & \\
\hline
\end{tabular}

*SD (standard deviation), OR (odds ratio), $\mathrm{Cl}$ (confidence interval)

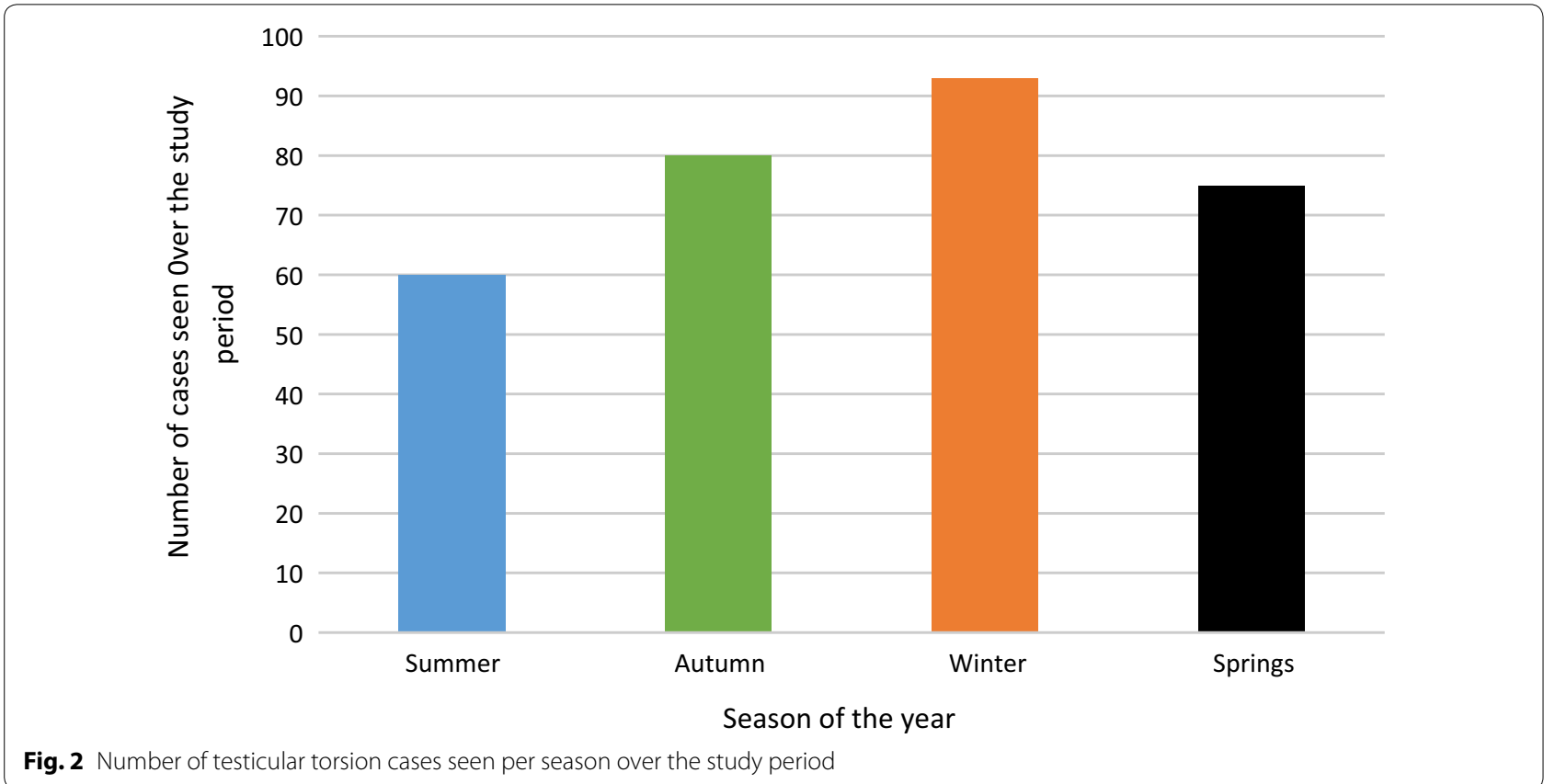

Table 3 Season of the year and age groups

\begin{tabular}{llllll}
\hline Age & Summer & Autumn & Winter & Spring & Total \\
\hline$<16$ & 29 & 32 & 35 & 35 & 131 \\
& 22.14 & 24.43 & 26.72 & 26.72 & 100.00 \\
$\geq 16$ & 31 & 48 & 58 & 40 & 177 \\
& 17.51 & 27.12 & 32.77 & 22.60 & 100.00 \\
Total & 60 & 80 & 93 & 75 & 308 \\
& 19.48 & 25.97 & 30.19 & 24.35 & 100.00 \\
\hline
\end{tabular}

Pearson chi2 $(3)=2.4732 \mathrm{Pr}=0.480$

and $2(0.65 \%)$ underwent a contralateral orchidopexy, the latter of which was because the affected testis atrophied. Over a third of patients presented within $24 \mathrm{~h}$ of onset $(35.7 \% ; n=110 / 308)$, of which the majority of these patients $(n=82 / 110 ; 74.5 \%)$ underwent a salvage surgery, or orchidopexy, and the remaining $25.5 \%$ required orchidectomy. The orchidectomy rate increased to $95 \%$
Table 4 Surgery and duration of symptoms

\begin{tabular}{|c|c|c|c|c|}
\hline \multirow[t]{2}{*}{ Type of surgery } & \multicolumn{4}{|c|}{ Onset of symptom to surgery in hours } \\
\hline & $<24 h$ & 24-72h & $>72 \mathrm{~h}$ & Total \\
\hline B/L Orchidopexy & $82(74.55)$ & $25(41.00)$ & $5(3.6)$ & $112(36.4)$ \\
\hline Orchidectomy & $28(25.45)$ & $36(59.00)$ & $130(95)$ & $194(63)$ \\
\hline $\begin{array}{l}\text { Contralateral orchi- } \\
\text { dopexy only }\end{array}$ & 0 & 0 & $2(1.4)$ & $2(0.6)$ \\
\hline Total & $110(100)$ & $61(100)$ & $137(100)$ & $308(100)$ \\
\hline
\end{tabular}

in those who had surgery beyond $72 \mathrm{~h}$ (Table 4), while the orchidopexy rate decreased to $3.6 \%$. Overall, in the 112 patients who underwent a bilateral orchidopexy, the time from onset of symptoms to surgery was significantly shorter at a median (IQR) of 13 (9-26) h, compared to 144 (40-264) $\mathrm{h}$ in the 194 patients who had an orchidectomy procedure $(p<0.0001)$. Specifically, the median time 
(IQR) from onset of symptoms to hospital admission, as well as from hospital admission to surgery, was both significantly shorter in the patients undergoing a bilateral orchidopexy compared to those having a orchidectomy at $9(6-21)$ versus $96(28-192)$ hours $(p<0.0001)$ and 3 $(2-5)$ versus $24(5-72) \mathrm{h}(p<0.0001)$, respectively.

Manual detorsion was performed in 32 patients (10.4\%) with the earliest being done within $3 \mathrm{~h}$ of the onset of symptoms and the latest at approximately $48 \mathrm{~h}$ after the onset of symptoms. Among those that had manual detorsion within $48 \mathrm{~h}$ of presentation, 28 (87.5\%) patients had a bilateral orchidopexy, while $4(12.5 \%)$ patients had orchidectomy.

\section{Discussion}

Testicular torsion is the twisting of the spermatic cord with the subsequent loss of the blood supply to the ipsilateral testicle. It may result from the lack of normal fixation of the testis or the epididymis to the cord or scrotum. Anatomically, two distinct types of testicular torsion are well described in different age groups: (1) extra-vaginal: torsion occurs at the level of the external inguinal ring in neonates. (2) intra-vaginal: a more common variety due to bell clapper deformity seen in adolescents and young adults [1-3].

In fact, it is a surgical emergency requiring prompt and urgent management because of the risk of irreversible testicular ischemic injury. Ischemia can occur as soon as $6 \mathrm{~h}$ after torsion, and the chance of saving the testis is reduced over the next $48 \mathrm{~h} \mathrm{[6]}$.

The degree of ischemia depends on the duration of torsion and the degree of rotation of the spermatic cord. Complete torsion occurs when the twisting is $360^{\circ}$ or greater with the absence of intratesticular flow on color Doppler; intermittent torsion is characterized by intermittent testicular pain of short duration with spontaneous resolution. In partial or incomplete torsion, the degree of torsion is less than $360^{\circ}$ with residual intratesticular perfusion and there is no spontaneous pain relieve [7].

Moreover, the condition is very painful and may wake the patient up from sleep [8]. The most common symptoms in testicular torsion are scrotal pain, swelling, erythema, nausea and vomiting. The lack of awareness and of the correct diagnostic knowledge for testicular torsion undoubtedly will lead to testicular death. Imaging or other diagnostic modality should not also be the cause of delay. However, in our institution in delayed presentation beyond 72-h imaging can be done and the absence of testicular flow and/or a positive whirlpool sign during color Doppler sonography (CDS), indicates the presence of testicular torsion [9].
As a matter of fact, different incidence rates of orchidopexy and orchidectomy have been reported in different articles from places around the world as follows: In America, 21,289 admissions with testicular torsion were identified using the Brazilian Public Health System Database from 1992 to 2010. The calculated annual incidence rate was 1.4:100,000 [10]. Asia, using the Taiwanese National Health Insurance Research Database from 1997 to 2010, subjects younger than 25 years with the diagnosis of testicular torsion were identified, $25.6 \%$ had orchiectomies and $74.4 \%$ orchiopexies. The estimated incidence was 3.5 per 100,000 person-years [11]. In Europe, a study done in England which was a prospective audit of 173 scrotal explorations for suspected testicular torsion from 1998 to 2008, 89 had testicular torsion and 16/89 (18\%) required an orchidectomy due to delayed presentation [12]. In Australia, pathology results of all testicular and paratesticular specimens from August 1995 to September 2007 were analyzed. Clinical details were retrieved retrospectively from the computerized database. Testicular torsion represented $11.2 \%$ with $68 \%$ for the left side [13]; about $52 \%$ of our patients in the current study have left-sided testicular torsion. In Africa, 90 patients with torsion of the testis from 1987 to 1991 enrolled in a study in Zimbabwe and found that the mean age was 17 years ( 2 months to 32 years); 71\% (64/90) presented within $72 \mathrm{~h}$ (mean delay $32 \mathrm{~h}$ ); $29 \%$ presented late $(>72 \mathrm{~h})$ with a mean delay of 7 days. The testicular salvage rate was $36 \%$ versus $64 \%$ orchidectomy rate [14]. Another African study in Nigeria by Udeh et al. showed instead an impressive orchidopexy rate of $75 \%$ [15].

In the present study, the mean age is $17.2 \pm 4.12$ years (range 10-33) and the accessible data used in this retrospective study show that the yearly trend of referrals is on the upward side. We believe that this may not be a true reflection of number of referrals as some files could not be retrieved due to poor record keeping, illegible handwriting particularly between 2006 and 2010; therefore, we could not further discuss such trend. However, one study by Bayne et al. reported an upward trend in number of referrals with testicular torsion from 3 in 2005 to 15 in 2015 before and after pediatric urology subspecialty certification [16].

The high orchidectomy rate of $63 \%$ observed in our study is a result of delayed presentation of the majority of patients for a definitive management with the median (IQR) time from onset of symptoms to hospital of $36 \mathrm{~h}$ $(10-168)$. The delay is noted to be more in the preadmission level. However, the orchidectomy rate in this study is higher compared with the $25.6 \%$ reported in the Taiwanese study and $18 \%$ in the England audit.

Surprisingly, the rate is about the same compared to the Zimbabwean study. An audit by Rampaul et al. found that 
delayed presentation to hospital was the most important contributing factor to testicular losses in testicular torsion in contrast to hospital delays which were not significant enough to impact on the outcome [17].

Peeraully et al. in a single center retrospective analysis of intraoperative findings relative to source of referral to a tertiary hospital for emergency scrotal exploration found that the orchidectomy rate was lower $(23 \%)$ in patients presented directly to their emergency department compared with those referred either from primary care centers (43\%) or transferred from other hospitals (50\%) [18].

As a tertiary hospital, patients seen in our department are either referred from primary care facilities or transferred from other non-tertiary hospitals. The incidence was not measured in this study owing to the fact that referrals to our facility came from different areas.

Another key point is that the degree of torsion and the duration of symptoms before scrotal exploration are important predictors of outcome in testicular torsion. There was a study that reported no testicle with a history longer than $12 \mathrm{~h}$ could be salvaged [19]. Another study by Bandarkar et al. reported testicular salvage up to 3 weeks for an incomplete testicular torsion [7]. In our study, testicular salvage was possible even beyond $72 \mathrm{~h}$ and surgical notes confirmed complete torsion. They may have had intermittent torsion or torsion detorsion syndrome but with complete torsion at the time of surgery.

Our study points out that in patients who presented within $24 \mathrm{~h}$ of onset, the salvage rate is as high as $75 \%$, while the orchidectomy rate is about $25 \%$. It also demonstrates that the orchidectomy rate increased to $95 \%$ in those who presented beyond $72 \mathrm{~h}$ (Table 4), while the orchidopexy rate decreased to $3.6 \%$. Orchidopexy was performed in those who demonstrated reperfusion after detorsion in theater where we usually base our assessment of viability on color changes from dusky to pinky after detorsion and wrapping of the testis in warm soaked surgical swab. Five of the patients presented beyond $72 \mathrm{~h}$ of onset in the study (3.6\%) had orchidopexy with time frame ranging from 73 to $816 \mathrm{~h}$ (about 5 weeks). A clinical study on 16 cases of testicular torsion by Sato et al. reported similar findings in 2 of 16 patients operated after $72 \mathrm{~h}$ and no testicular atrophy was noted one year after surgery [20]. Nonetheless, the earlier patients present to hospital, the higher the testicular salvage surgery rate is.

Most importantly, we found that the median duration from onset of symptoms to surgery in the orchidopexy group was shorter compared to the orchidectomy group at 13 (9-26) h and 144 (40264) h, respectively. The median duration from admission to surgery was also shorter in the orchidopexy group compared to the orchidectomy group at $3(2-5) \mathrm{h}$ and $24(5-72) \mathrm{h}$, respectively. The authors of a study in England demonstrating that most delay occurs outside hospital in managing testicular torsion, reported that patients were taken to the operating room within one hour and that the median time from onset of symptoms to surgery was $5.5 \mathrm{~h}$ in patients who had orchidopexy versus $42 \mathrm{~h}$ in patients who had orchidectomy [17]. Another study conducted in Croatia noted nearly similar findings $6 \mathrm{~h}$ in the orchidopexy group versus $46 \mathrm{~h}$ in the orchidectomy group [21]. Our study had the longest median duration compared to the other studies in both groups. Further studies with emphasis on the level of awareness; distance and transport issues; logistic issues during referral or transfer may be necessary to elucidate this findings.

Korkes et al. as well as Pogorelic et al. published studies supporting significant increase in incidence during colder months $[10,21]$. We also found that winter was the season with the highest number of referrals in both age groups $(26.7 \%$ in those $<16$ years and $32.77 \%$ in those $>16$ years) (Table 3); however, it was not statistically significant $(p=0.480)$. Testicular torsion was suggested to be more common during winter as the cremasteric reflex tends to occur more frequently in winter due to colder temperatures [22].

In our study, manual detorsion applied in 32 patients among those presented within $48 \mathrm{~h}$ of onset of symptoms was associated with a salvage surgery or testicular fixation surgery in 28 out of 32 (87.5\%) performed manual detorsion. This procedure which helps reduce the testicular ischemic time needs to always be followed by orchidopexy [23]. In our institution, we always strive to reduce to a minimum possible the time from admission to emergency surgery for every suspected testicular torsion presented within $72 \mathrm{~h}$. The median (IQR) time from admission to surgery in those presented within $72 \mathrm{~h}$ of onset being $3 \mathrm{~h}$, most of the time, due to emergency trauma cases (gun shots, stab wounds), hence manual detorsion as a routine part of management of testicular torsion will always find its significance in preventing more ischemic damages to the testis.

Surprisingly, there is no documented study in the literature that looked at the association between age and laterality of testicular torsion. This study is the first to examine such relationship and finds that patients aged $\geq 16$ years are 1.5 times likely to present with rightsided testicular torsion compared with those $<16$ years of age (OR 1.50, 95\% CI 0.95-2.37), though not significant $(p=0.080)$. Interestingly, the same study shows that for every 1-year increase in age, the odds of presenting with a right-sided testicular torsion increases by $6 \%$ (OR 1.06, 95\% CI 1.00-1.12, $p=0.047$ ).

There is no study in the literature highlighting the clinical significance of older patients to present mostly with 
right-sided testicular torsion as noted in this cohort. Further studies might be needed in the future to assess its clinical significance.

Nevertheless, limitations of the study included: reliance on the data as they were collected (timing, patients' details); the record keeping system in theater and in the filing department is not electronic; hence, some files could not be retrieved due to names misspelled, hospital number not accurately entered in the registry, illegible handwriting. Follow-up notes to assess viability or atrophy particularly for orchidopexy beyond $72 \mathrm{~h}$ were not available as outpatients use an outpatient file that they keep.

As a retrospective study, the reason of preadmission delay for each individual patient could not be established; hence, we assume that the delay might have been caused by one of the following: lack of awareness; misdiagnosis; distance and transport issues; logistic issues when arranging transfer.

\section{Conclusion}

We report that delayed management of testicular torsion is relative to pre-admission delay for testicular torsion and that these delays significantly impact on the testicular loss and salvage rates. There is a significant association between the pre-surgery duration of symptoms and the type of surgery. Testicular salvage is possible beyond $72 \mathrm{~h}$ from the onset of symptoms, although the salvage rate reduces from $75 \%$ within $24 \mathrm{~h}$ to $3.6 \%$ beyond $72 \mathrm{~h}$. The testicular salvage rate is higher, the earlier patients present.

In addition, the overall median time from admission to surgery in our urology unit is $6 \mathrm{~h}$ and decreases to $3 \mathrm{~h}$ for patients who present within $72 \mathrm{~h}$. Furthermore, manual detorsion was found to be an important management tool as close to $88 \%$ of manually untwisted testes had salvage surgery.

Interestingly, our study is the first to look at age and laterality of testicular torsion and we report that for every 1 -year increase in age, the odds of presenting with a right-sided testicular torsion increases by $6 \%$.

\section{Abbreviations}

CDS: Color Doppler sonography; CHBAH: Chris Hani Baragwanath Academic Hospital; Cl: Confidence interval; IQR: Interquartile range; OR: Odds ratio; SD: Standard deviation.

\section{Acknowledgements}

A special thanks to Oluwatosin Ayeni for helping out with statistical analysis.

\section{Author contributions}

AMM substantially contributed to conception of the study, to obtain ethical approval, drafting, reviewing for critical content, editing of the manuscript. DK supervised, reviewed for critical content and edited the manuscript. MH supervised, reviewed for critical content. They all approved the final version of the manuscript.
Funding

This study had no funding from any resource.

\section{Availability of data and materials}

The datasets used during the current study are available from the corresponding author on reasonable request.

\section{Ethics Approval and Consent to Participate}

This study was approved by the Wits-Human Research Ethics Committee, Reference Number of Approval: M190761. All procedures performed in this study were in accordance with the ethical standards of the Wits-Human Research Ethics Committee and with the 1964 Helsinki Declaration and its later amendments or comparable ethical standards. This was a retrospective study using patients records so consent to participate is not applicable.

\section{Consent for publication}

Not applicable.

\section{Competing interests}

The authors declare that they have no competing interests.

\section{Author details}

${ }^{1}$ Division of Urology, Department of Surgery, School of Clinical Medicine, Faculty of Health Sciences, University of the Witwatersrand, Johannesburg, South Africa. ${ }^{2}$ Department of Surgery, School of Clinical Medicine, Faculty of Health Sciences, University of the Witwatersrand, Johannesburg, South Africa.

Received: 24 February 2020 Accepted: 17 June 2020

Published online: 30 July 2020

\section{References}

1. Beni-Israel T, Goldman M, Bar Chaim S, Kozer E (2010) Clinical predictors for testicular torsion as seen in the pediatric ED. Am J Emerg Med. 28(7):786-9

2. Erdogan A, Gunay EC, Gundogdu G, Avlan D (2011) Testicular torsion in the left inguinal canal in a patient with inguinal hernia: a difficult case to diagnose. Mol Imaging Radionucl Ther 20(3):108-110

3. Riaz-UI-Haq M, Mahdi DEA, Elhassan EU (2012) Neonatal testicular torsion; a review article. Iran J Pediatr 22(3):281-289

4. Ramachandra P, Palazzi KL, Holmes NM, Marietti S (2015) Factors influencing rate of testicular salvage in acute testicular torsion at a tertiary pediatric center. West J Emerg Med 16(1):190-194. https://doi.org/10.5811/ westjem.2014.11.22495

5. Molokwu CN, Somani BK, Goodman CM (2011) Outcomes of scrotal exploration for acute scrotal pain suspicious of testicular torsion: a consecutive case series of 173 patients. BJU Int 107(6):990-993

6. Ringdahl E, Teague $L$ (2006) Testicular torsion. Am Fam Phys 74(10):1739-1743

7. Bandarkar AN, Blask AR (2018) testicular torsion with preserved flow: key sonographic features and value added approach to diagnosis. Pediatr Radiol 48(5):735-744

8. Cuckow PM, Frank JD (2000) Torsion of the testis. BJU Int 86:349-353

9. McDowall J, Adam A, Gerber L, Enyama COA, Aigbodion SJ, Buchanan S (2018) The ultrasonographic "whirlpool sign" in testicular torsion: valuable tool or waste of valuable time? A systematic review and metaanalysis. Emerg Radiol 25:281

10. Korkes F, Cabral PR, Alves CD, Savioli ML, Pompeo AC (2012) Testicular torsion and weather conditions: analysis of 21,289 cases in Brazil. Int Braz J 38(2):222-229

11. Huang WY, Chen YF, Chang HC, Yang TK, Hsieh JT, Huang KH (2013) The incidence, rate and characteristics in patients with testicular torsion: a nationwide, population-based study. ActaPaediatr 102(8):e363-e367

12. Somani B, Watson G, Townell N (2010) easily missed?. Testicular torsion, BMJ July

13. Marulaiah M, Gilhotra A, Moore L, Boucaut H, Goy DW (2010) Testicular and paratesticular pathology in children: a 12-year histopathological review. World J Surg 34(5):969-974

14. Muguti Gl, Kalgudi R (1994) Torsion of the testis: review of clinical experience in Zimbabwe-Cent. Afr J Med 40(5):119-22 
15. Udeh FN (1985) Testicular torsion: Nigerian experience. J Urol 134:482-484

16. Bayne CE, Gomella PT, DiBianco JM, Davis TD, Pohl HG, Rushton HG (2017) Testicular torsion presentation trends before and after pediatric urology subspecialty certification. J Urol 197(2):507-515

17. Rampaul MS, Hosking SW (1998) Testicular torsion: most delay occurs outside hospital. Ann R coll Surg Engl 80:169-172

18. Peeraully R, Jancauskaite M, Dawes S (2019) Does the source of referral affect outcomes for paediatric testicular torsion? Ann R Coll Surg Engl 101(6):1-4

19. Jefferson $R H$, Perez LM, Joseph DB (1997) Critical analysis of the clinical presentation of acute scrotum: a 9-year experience at a single institution. J Urol 158(3 Pt 2):1198-1200
20. Sato N, Lee Z, Fujita M (1989) clinical study on 16 cases of testicular torsion. Hinyokika kiyo 35(11):1877-1880

21. Porogelic Z, Mustapic K, Jukic M, Todoric J, Mrklic I, Messtrovic J et al (2016) Management of acute scrotum in children: a 25-year single center experience on 558 pediatric patients. Can J Urol 23(6):8594-8601

22. Mellick LB, Al-Dhahir MA (2020) Cremasteric Reflex. StatPearls [Internet]. StatPearls Publishing, Treasure Island (FL)

23. Demirbas A, Demir DO, Ersoy E et al (2017) Should manual detorsion be a routine part of treatment in testicular torsion? BMC Urol 17:84

\section{Submit your manuscript to a SpringerOpen ${ }^{\circ}$ journal and benefit from:}

- Convenient online submission

- Rigorous peer review

- Open access: articles freely available online

- High visibility within the field

- Retaining the copyright to your article

Submit your next manuscript at $\boldsymbol{\sim}$ springeropen.com 